\title{
Experimental study of circular inlets effect on the performances of Gas-Liquid Cylindrical Cyclone separators (GLCC)
}

\author{
Ho Minh Kha ${ }^{1}$, Nguyen Thanh Nam ${ }^{2, *}$, Vo Tuyen ${ }^{3}$, Nguyen Tan Ken ${ }^{3}$
}

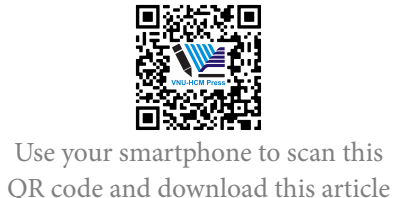

QR code and download this article

\begin{abstract}
The gas-liquid cylindrical cyclone (GLCC) separators is a fairly new technology for oil and gas industry. The current GLCC separator, a potential alternative for the conventional one, was studied, developed and patented by Chevron company and Tulsa University (USA). It is used for replacing the traditional separators that have been used over the last 100 years. In addition, it is significantly attracted to petroleum companies in recent years because of the effect of the oil world price. However, the behavior of phases in the instrument is very rapid, complex and unsteady which may cause the difficulty of enhancing the performance of the separation phases. The multiple recently research show that the inlet geometry is probably the most critical element that influences directly to the performance of separation of phases. Though, so far, most of the studies of GLCC separator were limited with the one inlet model. The main target of the current study is to deeply understand the effect of different geometrical configurations of the circular inlet on performances of GLCC by the experimental method for two phases flow (gas-liquid). Two different inlet configurations are constructed, namely: One circular inlet and two symmetric circular inlets. As a result, we propose the use of two symmetric circular inlets to enhance the separator efficiency because of their effects. Key words: Gas-liquid cylindrical cyclone separator, GLCC, cyclone separator, multiphase flow
\end{abstract}

${ }^{1}$ Ho Chi Minh City University of Technology and Education (HCMUTE), Vietnam

${ }^{2}$ DCSELAB, Faculty of Mechanical Engineering, Ho Chi Minh City University of Technology, VNUHCM, Vietnam

${ }^{3}$ Ho Chi Minh City University of Food Industry (HUFI), Vietnam

Correspondence

Nguyen Thanh Nam, DCSELAB, Faculty of Mechanical Engineering, Ho Chi Minh City University of Technology, VNUHCM, Vietnam

Email: thanhnam@dcselab.edu.vn

History

- Received: 17-10-2018

- Accepted: 30-12-2018

- Published: 31-12-2019

DOI : 10.32508/stdjet.v3iSI1.732

\section{Check for updates}

\section{Copyright}

(c) VNU-HCM Press. This is an openaccess article distributed under the terms of the Creative Commons Attribution 4.0 International license.

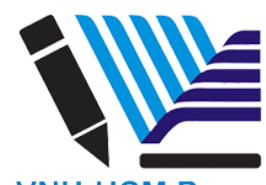

VNU-HCM Press

\section{INTRODUCTION}

In the petroleum industry, separating the single phases of gas and liquid from a multiphase product is an important stage of the production process. The tradition type separators, that have been popularly used for this work, are big, heavy, bulky, and costly in purchasing and operating. The gas-liquid cylindrical cyclone (GLCC) separator, a potential substitute for the conventional one, was patented by Chevron Petroleum Technology Company and Tulsa University ${ }^{1}$.

The GLCC is a simple, compact, low-weight, low inhabitancy time and the low-cost separator that is rapidly gaining popularity as an alternative to conventional gravity-based separators. Shown in Figure 1 is a GLCC consisting of a vertical pipe with a tangential inlet and outlets for gas and liquid. The tangential flow from the inlet to the body of the GLCC causes the flow to swirl with sufficient tangential velocity to produce centripetal forces on the entrained which are an order of magnitude higher than the force of gravity. The combination of gravitational and centrifugal forces pushes the liquid radially outward and downward toward the liquid exit, while the gas is driven inward and upward toward the gas exit ${ }^{1-3}$.

The operational envelope of a GLCC is described by two phenomena: Liquid carry-over (LCO) in the gas stream and gas carry-under (GCU) in the liquid stream. The start of liquid carry-over is identified by the first trace of liquid in the gas stream. Similarly, the first visible bubbles in the liquid underflow mark the onset of gas carry-under. The difficulty in developing accurate performance predictions arises largely from the variety of complex flow patterns that can occur in the GLCC. The flow patterns above the inlet can include bubble, slug/churn, annular-dispersed, and liquid ribbon flow. Below the inlet, the flow generally consists of a liquid vortex with a gas-core filament. Although they have potential applications, the complex phenomenon affecting the separating efficiency have not been studied completely in the past ${ }^{1,4-6}$.

This difficulty in predicting the hydrodynamic performance of the GLCC has been the single largest obstruction to broader use of the GLCC. Even without tried and tested performance predictions, several successful applications of GLCC's have been reported ${ }^{3}$. The development of reliable performance-prediction tools will improve GLCC's through hardware modifications and, ultimately, will govern the speed and extent to which GLCC technology is deployed in existing and new field applications. Recent laboratory observations and computer simulations indicate that hardware modifications to the GLCC can have a profound effect on GLCC performance ${ }^{2}$. The GLCC perand Technology; 2(SI1):SI164-SI173. 


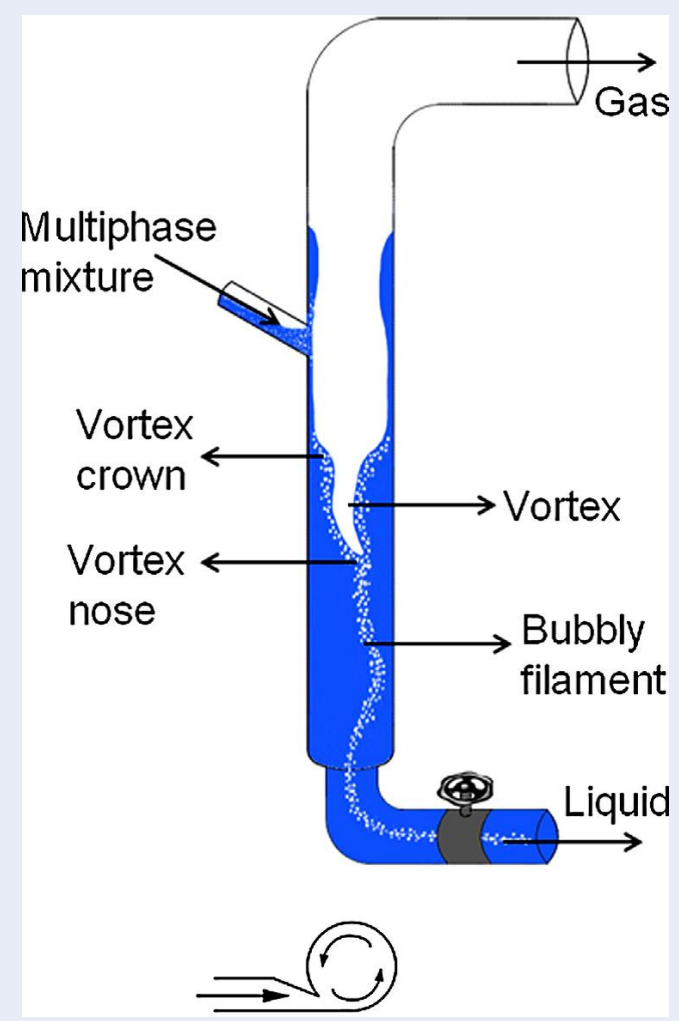

Figure 1: The Gas-Liquid Cylindrical Cyclone separator.

formance is dependent upon the tangential velocities of the swirling fluids, especially that of the liquid. The inlet is the single most redesigned component of the GLCC because of the inlet's influence on tangential velocity $^{1,2}$. Kouba and Shoham ${ }^{1}$ observed experimentally that the optimal inclined inlet angle is $27^{\circ}$ which allowed to retard significantly the onset of liquid carry-over (LCO) in comparison with the horizontal inlet.

Most of the previous studies of GLCC separator were limited with the one inlet model ${ }^{7-10}$. Movafaghian et al. ${ }^{11}$ researched the effects of geometry, fluid properties and pressure on the hydrodynamics of GLCC with one and two inlets. But the two inlets is the same of the side.

Recent studies, they propose the use of multiple tangential inlets to improve separation efficiency in GLCC. Such inlet configuration leads to lower swirl intensity decay than the unique inlet configuration. It also engenders a more axisymmetric flow, which would improve the GLCC performance with respect to $\mathrm{LCO}^{12-15}$. Thus far, over the past 22 years, more than 6500 GLCCs have been installed around the world by the petroleum and related industries ${ }^{16}$. However, the research has not been conducted on two symmetric inlet types to compare the effect of one type of inlet with the same angle of inclination and the area of the nozzle when it uses to separator multiphase.

\section{METHODOLOGY OF RESEARCH - EXPERIMENTAL INVESTIGATION}

The GLCC' geometry is modeled size parameters along with experimental models of Hreiz. R et al. ${ }^{13,14}$ (Figure 2). According to the diameter size of the pipe available on the market, in this investigation, two different inlet configurations (Figure 3) are constructed with the same inclined inlet is $27^{\circ}$ and the crosssectional area of the inlet was approximately (27$28 \%$ ) compared to the cross-sectional area of GLCC. The two-phase mixture is introduced into the GLCC through a Y junction and the static mixer (Figure 4). The schematics of the GLCC test section shows in Figure 5. The experimental facility meets the following requirements:

- Two-phases (air-liquid), full separator.

- Easy and quick change of different inlet configurations. 
- The GLCC body is transparent to allow visualizations and is manufactured in Acrylic

- The inlets are manufactured by stainless steel.

- One phase, $1 \mathrm{HP}$ centrifugal pump, capable of producing 5-266 L/min (at max. head of $22 \mathrm{~m}$ ).

- One phase, 3HP ring blower, capable of producing $325 \mathrm{~m}^{3} / \mathrm{h}$ (at max. head of $36 \mathrm{KPa}$ ).

- Two rotameters $\left(1.6-16 \mathrm{~m}^{3} / \mathrm{h}\right)$ and flow rate measurement tree to measure flow rates for different inlet configurations.

- One measures air flow

- A 120 liters storage tank

- Two static mixers

Two gas-liquid phases are supplied from the centrifugal pump and the gas blower. The mixture before entering the GLCC is mixed together through a static mixer. Inside the GLCC body, after phase separation, the gas phase escapes in the upper direction and passes through the cyclone to remove frost, clean air goes out, separated fog is collected again to measure and then return to the tank. The liquid phase after passing through the GLCC will drain in the downward direction and return to the tank.

\section{RESULTS}

In the GLCC upper part, liquid droplets are pushed toward the walls by centrifugal force and combine into a liquid layer. As this liquid layer is compact compared to discrete droplets, the gas flow will have more difficulties to take it up to the top outlet. The liquid from the wall layer falls down by gravity into the liquid vortex thereafter. However, if the gas flow rate is increased beyond a certain threshold, the liquid is carried over with the gas stream in the GLCC upper outlet. This limiting phenomenon is called Liquid CarryOver (LCO) ${ }^{14}$.

The LCO in the gas stream is largely dependent on the flow pattern in the upper part of the GLCC. Flooding may occur in the GLCC at high liquid levels and low gas rates, producing bubbly flow. The unsteady liquid fluctuations, characteristic of churn flow at moderate gas rates, may jump liquid into the gas outlet. The liquid can also be carried out in droplets at the onset of annular mist flow at high gas rates. At very high gas rates, the centrifugal force of the swirling gas pushes the liquid to the wall of the pipe, where it may form an upward-spiraling continuous ribbon of liquid ${ }^{1,2,17}$.

In our study, the GLCC is operated under conditions of LCO. When the superficial gas velocity in the cylindrical (Vsg) decreases from about $9 \mathrm{~m} / \mathrm{s}$ to about 1 $\mathrm{m} / \mathrm{s}$ and simultaneously, the superficial liquid velocity (Vsl) in the cylindrical increases from $0.1 \mathrm{~m} / \mathrm{s}$ to
$0.5 \mathrm{~m} / \mathrm{s}$. The upper flow component of the GLCC also transitions from the annular flow to the flow churn (Figure 6) as the one inlet is used. However, when using the two-inlet type, the velocity value of Vsg and Vsl inside the cylindrical will be higher than the one inlet of the operational envelope of LCO. Effect of inlet geometry on the operational envelope for LCO threshold are presented below.

Annular flow ${ }^{18}$ is a flow regime of two-phase gasliquid flow. It is characterized by the presence of a liquid film flowing on the channel wall (in a round channel this film is annulus-shaped which gives the name to this type of flow) and with the gas flowing in the gas core. The flow core can contain entrained liquid droplets. In this case, the region is often referred to as annular-dispersed flow, where the entrained fraction may vary from zero (a pure annular flow) to a value close to unity (a dispersed flow). Often both types of flow, pure annular and annular-dispersed, are known under the general term of annular flow (Figure $6 \mathrm{a}$ ).

The churn flow LCO regime the churning flow (Figure $6 \mathrm{~b}$ ) is a very chaotic and turbulent regime characterized by unstable vertical oscillations of the flow that can occur for moderate to high liquid flow rates. According to our visual observations, beyond a certain air flow rate, the USLF (Upper Liquid Swirling Film) is destabilized, mainly because of the air flow that tries to lift it up. Thus, the USLF loses its integrity, which results in a churn flow regime with violent oscillations just above the inlet level. Liquid droplets are ejected from the churn flow region and may splash up to the gas outlet, thereby initiating the LCO. If the gas flow rate is increased further, more liquid is lifted by the gas, and the churn flow regime invades all the upper part of the GLCC ${ }^{14,19}$.

With two symmetric inlets and when the GLCC is operated in a state of churn flow (Vsg $<4 \mathrm{~m} / \mathrm{s}$ and $\mathrm{Vsl}>$ $0.25 \mathrm{~m} / \mathrm{s}$ ). The flow in the upper of the GLCC fluctuates very strongly and continuously changes. It is characterized by the presence of a very thick and unstable liquid film, with the liquid often oscillating up and down in cycles (Figure 7). But, there is a really interesting which is the oscillation around the tube is relatively uniform when using the two inlet type compared to the other inlet. This will affect the performance of the separator.

In the GLCC lower part, if the swirl intensity is high enough, the free gas-liquid interface gets carved out and the vortex can be observed. The liquid flows from the inlet nozzle to the vortex in a thin swirling film (Figure 1), to which we will refer to as Lower Swirling 


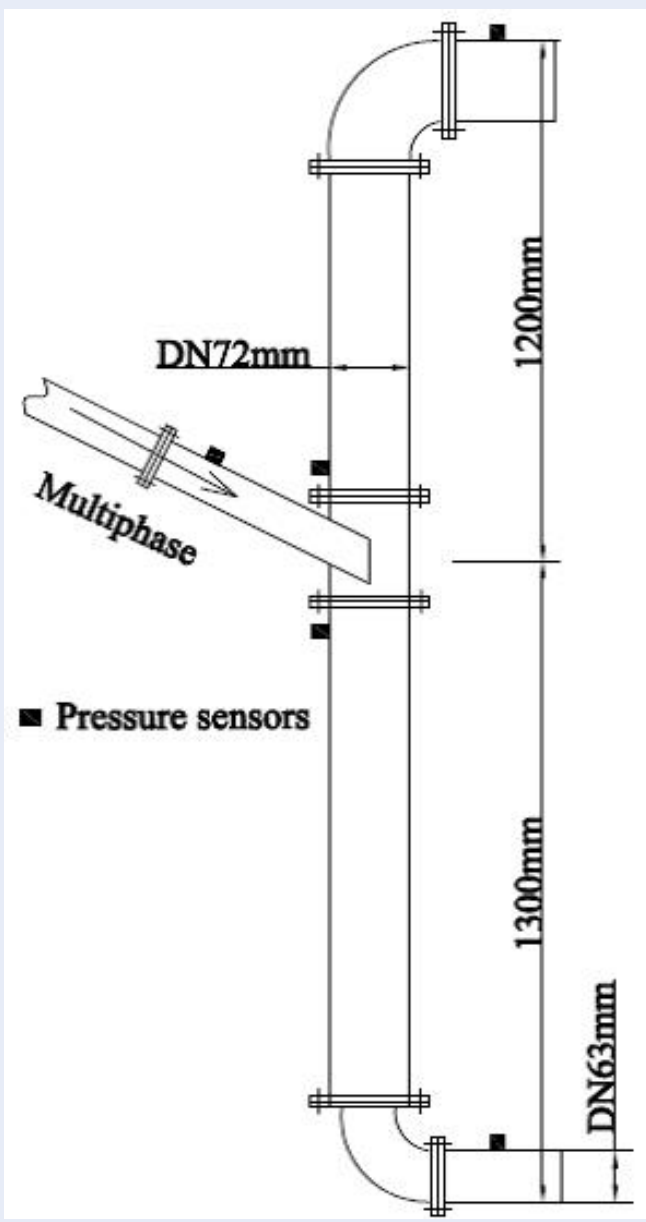

Figure 2: Main dimensions of the GLCC.

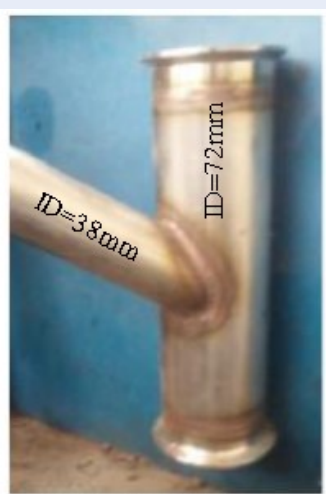

One circular inlet (I.D $38 \mathrm{~mm}$ )

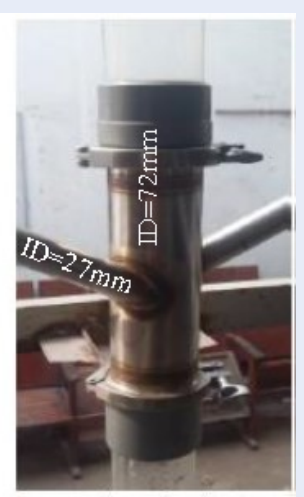

Two circular inlets (I.D $27 \mathrm{~mm}$ )

Figure 3: The different inlet configurations. 


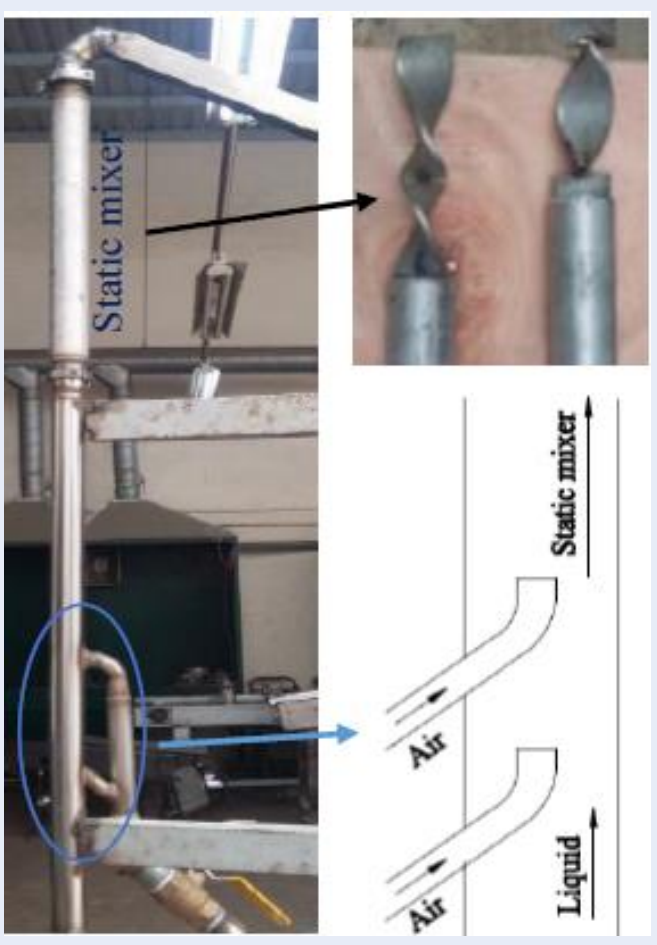

Figure 4: The $Y$ junction and static mixer.

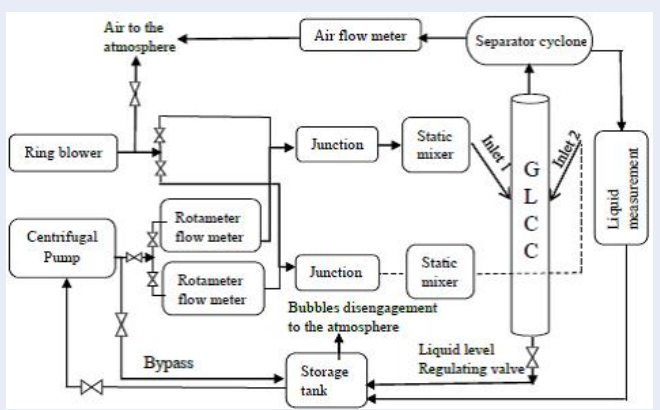

Figure 5: Schematics of the GLCCtest section.

Liquid Film, LSLF. Large bubbles quickly move toward the free interface due to buoyancy. Smaller bubbles, while being dragged downward by the liquid, are pushed radially toward the vortex center. They form a bubbly filament which allows a nice visualization of the vortex core. These bubbles are supposed to rise up to the free interface and to disengage ${ }^{1,14}$.

A variety of experiments has been conducted with the both of the inlets to investigate the different flow patterns in the lower part of the GLCC. The study was restricted to gas-liquid flow rates upper the LCO limit. The top part of the vortex, the crown, was maintained about $100 \mathrm{~mm}$ below the inlet nozzle through a valve installed on the GLCC lower outlet (Figure 5). The vortex level was not set closer to the entrance level for two reasons. The first reason is that in field conditions, gas and liquid flow rates fluctuate in time. Thus, the vortex level in the GLCC must be maintained at a certain distance from the inlet, so that the control system has enough time to react in the case of a sudden increase of the liquid flow rate, and prevents the vortex to exceed the inlet level and to lead to a precocious LCO. The second reason is that when the vortex level is too close to the entrance, we observed that the flow gets disrupted. As noticed by Shoham and $\mathrm{Kouba}^{2}$, some distance from the entrance is necessary 


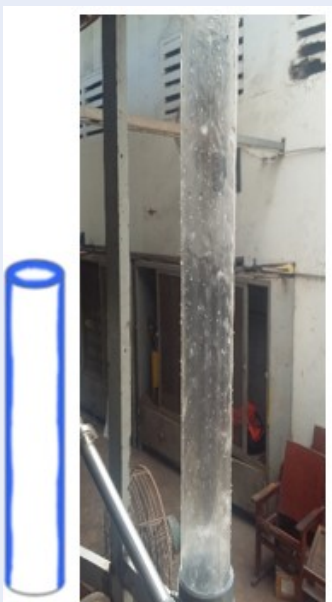

(a) Annular flow

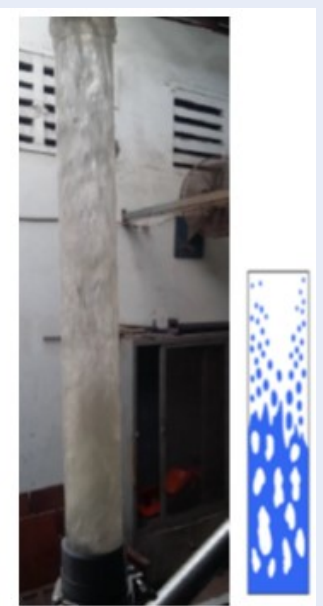

(b) Churn flow

Figure 6: Schematics of different LCO flow regimes.

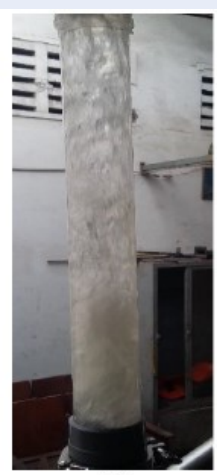

(a)

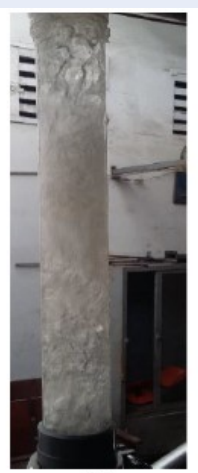

(b)

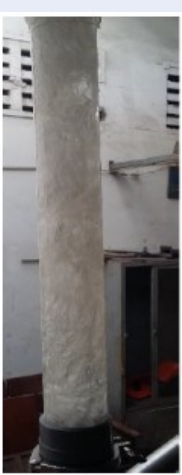

(c)

Figure 7: Fluctuations up and down in cycles of the churnflow LCO regime.

to achieve an optimal swirl intensity ${ }^{14}$.

Based on visual observations, the bubbly filament presents a very complex hydrodynamics. The flow pattern depends mainly on the liquid flow rate and the number of the inlet. An increase in the gas flow rate has little effect on the flow pattern but increases the number of bubbles in the flow. As Vsl increases and Vsg decreases, the flow pattern is characterized by important centrifugal forces and so, the vortex becomes deeply excavated and shows tortuosities. Bubbles tend to be smaller and, as the swirl intensity becomes higher, most of the bubbles concentrate in the filament, and bubble dispersion decreases (Figure 8). The warping of the vortex comes from the use of a unique inlet nozzle, which induces a pronounced asymmetry in the flow. Extremely few bubbles are found outside the region around the bubbly filament and the zone near the vortex interface.
Figure 9 displays the filament core of a one and two circular inlets. The upward and downward flow region near the cylindrical center line for one inlet has a helical (spiral) shape. But, the upward and downward flow region near the cylindrical center line of two nozzle inlets is a quite axisymmetric flow field. In GLCC's design, this means that there is more space to capture bubbles at the center and uplift them to the gas-liquid interface for the separation.

\section{DISCUSSION}

In order to determine the start of liquid carry-over LCO for a given liquid flow rate, a series of experiments is done at a fixed liquid flow rate. A gas flow rate is chosen, the mixture is introduced into the GLCC, and it is observed whether or not the liquid reaches the upper outlet. 


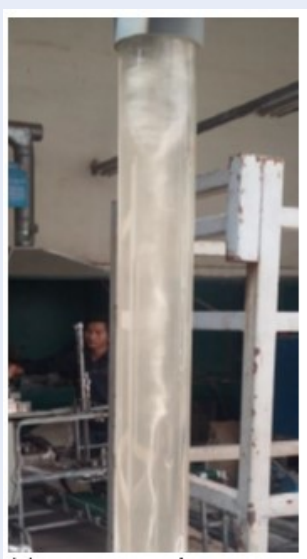

(a) Excavated vortex flow $\quad(\mathrm{Vsl}=0.27 \mathrm{~m} / \mathrm{s}$, $\mathrm{Vsg}=10.5 \mathrm{~m} / \mathrm{s}$

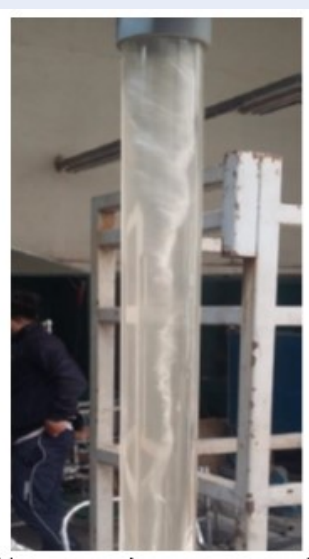

(b) Deeply excavated vortex flow $(\mathrm{Vsl}=0.41 \mathrm{~m} / \mathrm{s}$, $\mathrm{Vsg}=6.4 \mathrm{~m} / \mathrm{s}$

Figure 8: Different vortex regimes in the GLCC lower part (casetwo inlets is used).

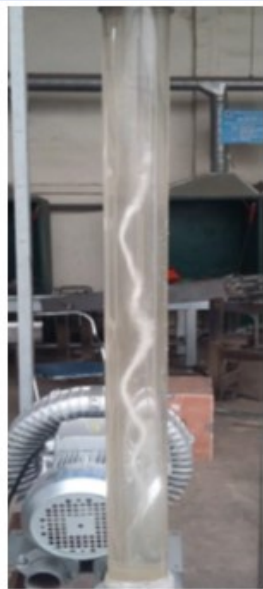

One circular inlet

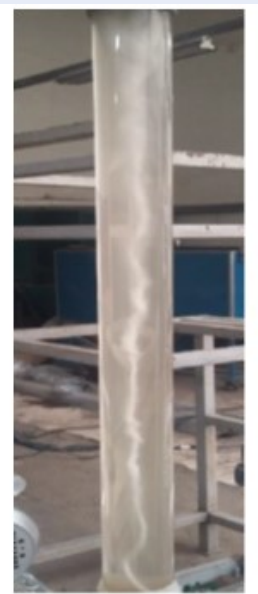

Two circular inlets

Figure 9: The filament core in the GLCC lower part.

Figure 10 shows the variations of the operational envelope for LCO threshold with the GLCC inlet configurations, at atmospheric pressure for an air-water system. Two different inlet configurations were used: a $38 \mathrm{~mm}$ I.D single-inlet and $27 \mathrm{~mm}$ I.D for two symmetric inlets.

Comparison between the LCO operational envelopes for them reveals that the operational envelope of LCO expands significantly for the two symmetric inlets than the operational envelope of LCO for single-inlet. It demonstrates that, the performance of the two symmetric inlets better than the performance of singleinlet for conditions approaching the operational envelope for LCO.
In addition, to increase the reliability of research data, the comparison between the present data and the data reported by Movafaghian et al. ${ }^{11}$ is presented in Figure 11. Note that the present data are for a $72 \mathrm{~mm}$ ID GLCC while the data of Movafaghian et al. were obtained for a $76.2 \mathrm{~mm}$ ID GLCC ${ }^{11}$. Then, this pipe area is gradually reduced by placing a plate within the inlet pipe to reduce the inlet area to about $25 \%$ of the area of the cylinder (crescent nozzle). The results show that the operational envelope of Movafaghian et al. ${ }^{11}$ data expands lightly compared to the other. This is consistent with the research results of Shoham and $\mathrm{Kouba}^{2}$ that the concentric-circular nozzle configuration had the poorest performance, while the crescent 


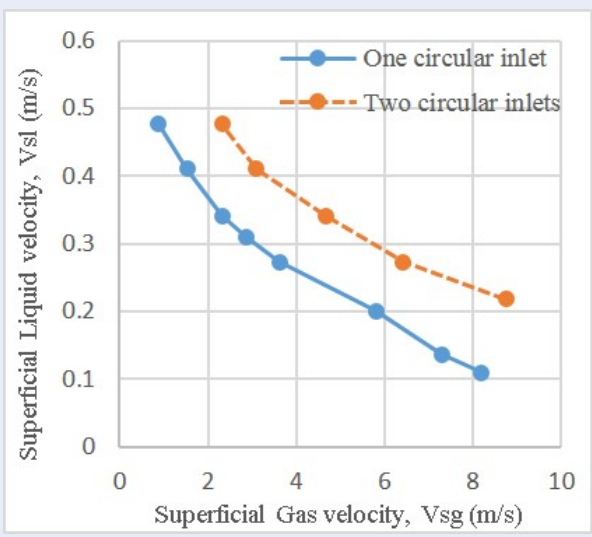

Figure 10: Effect of inlet geometry on the operational envelope for liquid carry-over (LCO) threshold.

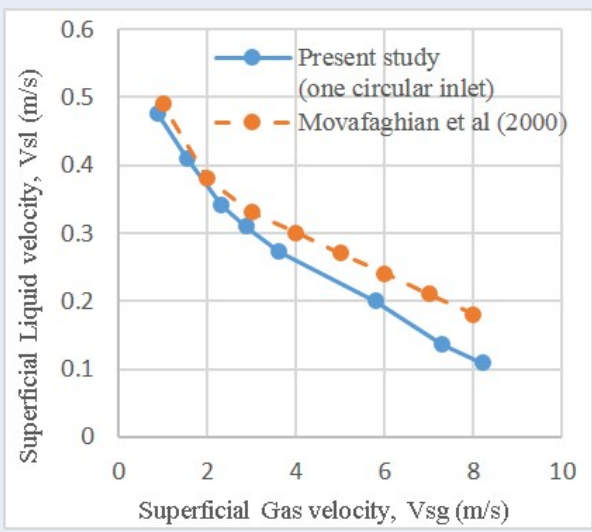

Figure 11: Comparison of the operational envelope for liquid carry-over (LCO) threshold ${ }^{11}$

nozzle performed closest to the rectangular slot with the same cross-sectional area.

A series of experiments were conducted to compare the performance of GLCC, the top part of the vortex, the crown, was maintained about $100 \mathrm{~mm}$ below the inlet nozzle. Test results show that the effect of structure and number of inlets has a clear impact on the performance of the separator. When using the two symmetric inlets type, the separation efficiency of liquid is higher than the separation efficiency of liquid for the one-inlet type (Figure 12).

\section{CONCLUSIONS AND RECOMMENDATIONS}

For the GLCC design, besides cylindrical cyclone diameter, the inlet nozzle geometry is probably the most important parameter because it controls directly the

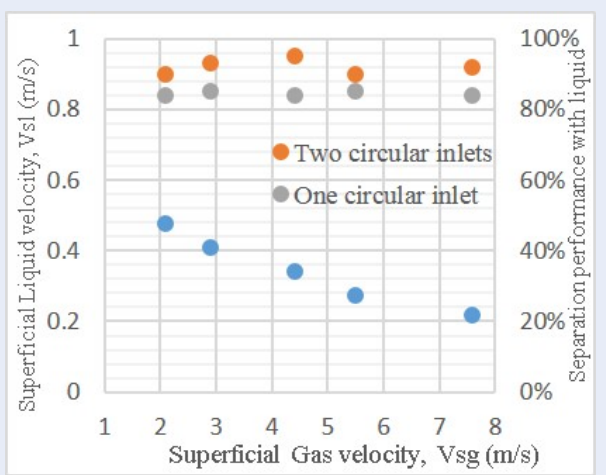

Figure 12: Separation performance with liquid.

swirl intensity in the flow ${ }^{14,16}$. In this research, the effect of two different nozzles design of inlet on the hydrodynamics and the performances of a gas-liquid cylindrical cyclone (GLCC) working in a full gaswater separator configuration was investigated by experiments. The measure has been used as a potential tool to ameliorate the influence of the different geometrical configurations of the inlet on complex flow patterns of the GLCC separators. The following conclusions can be extracted from this study:

Comparison of the operational envelopes for LCO reveals that the two symmetric inlet configuration is superior to the single-inlet.

The separation efficiency of the device will be higher when using two symmetric inlets. However, the manufacturing is more difficult and takes up more space than the other. In addition, the two-phase flow balance for the two inlets should also be considered.

Finally, we suggest the application of two symmetric inlets type that is the same angle of inclination and the area of the nozzle with the unique inlet configuration to improve separation efficiency in GLCC. Such inlet structure leads to lower swirl intensity decay than one inlet configuration. Besides, it also creates a more axis symmetric flow at the center line, which would improve the uplift of air bubbles in the performance of GLCC.

\section{ACKNOWLEDGEMENTS}

This research is supported by DCSELAB and funded by Vietnam National University HoChiMinh City (VNU-HCM) under grant number C2018-20b-01. We appreciate highly the great support of DCSELAB which allowed and gave us a lot of facilities to perform the experiments and this paper. 


\section{LIST OF ABBREVIATIONS}

GLCC: Gas-Liquid Cylindrical Cyclone

LCO: Liquid Carry-Over

GCU: Gas Carry-Under

USLF: Upper Liquid Swirling Film

ID: Iner Diameter

\section{CONFLICT OF INTEREST}

There is no conflict of interest.

\section{AUTHOR'S CONTRIBUTION}

The authors declare that all authors discussed the results and contributed to the final manuscript.

\section{REFERENCES}

1. Kouba GEA, Shoham O. Review of gas-liquid cylindrical cyclone technology. International Conference of Production Separation Systems, Aberdeen, UK. 1996;

2. Shoham O, Kouba GE. State of the art of gas/liquid cylindricalcyclonecompact-separator technology. SPE. 1998;2-5:462471.

3. Arpandi I, et al. Hydrodynamics of Two-Phase Flow in Gas/Liquid Cylindrical-Cyclone Separators. SPE Journal. 1996;p. 427. Available from: https://doi.org/10.2118/30683PA.

4. Gomez LE, Mohan RS, Shoham O, Marrelli JD, Kouba GE. Stateof-the-art simulator for field applications of gas-liquid cylindrical cyclone separators. SPE Annual Technical Conference and Exhibition, Houston, Texas . 1999;Available from: https: //doi.org/10.2118/56581-MS.

5. Erdal F, Shirazi S. Local velocity measurements and computational fluid dynamics (CFD) simulations of swirling flow in a gas-liquid cylindrical cyclone separator. Engineering Technology Conference on Energy, Texas. 2001;15:23-30.

6. Mohan R. Internal report. TUSTP. 2013;PMID: 23845670. Available from: https://doi.org/10.1136/bcr-2013-008665.

7. Hreiz R, Gentric C, Midoux N. Numerical investigation of swirling flow in cylindrical cyclones. Chem Eng Res Des. 2011;89:2521-2539. Available from: https://doi.org/10.1016/ j.cherd.2011.05.001.
8. Sy LV. Nghiên cứu động lực học dòng chảy trong bộ tách lọc dầu/khí GLCC. Tuyển tập công trình hội nghị khoa học cơ học thủy khí toàn quốc năm 2015. 2015;

9. Sy LV. Influence of inlet angle on flow pattern and performance of gas-liquid cylindrical cyclone separator. Particulate Science And Technology. 2016;Available from: http://dx.doi. org/10.1080/02726351.2016.1180336.

10. Kolla S, Mohan S, Shoham O. Experimental investigation of liquid carry-over in GLCC separators for 3-phase flow. ", Paper No IMECE2016-67457, 10 pages;p. V007T09A006. Available from: https://doi.org/10.1115/IMECE2016-67457.

11. Movafaghian S, et al. The effects of geometry, fluid properties and pressure on the hydrodynamics of gas-liquid cylindrical cyclone separators. International Journal of Multiphase Flow. 2000;26:999-1018. Available from: https://doi.org/10. 1016/S0301-9322(99)00076-2.

12. Erdal F, Shirazi S. Effect of inlet configuration on flow behavior in a cylindrical cyclone separator. ASME Eng Technol Conf on Energy. 2002;Available from: https://doi.org/10.1115/ ETCE2002/MANU-29110.

13. Hreiz R. Hydrodynamics and velocity measurements in gasliquid swirling flows in cylindrical cyclones. Chemical engineering research and design. 2014;Available from: https://doi. org/10.1016/j.cherd.2014.02.029.

14. Hreiz R, et al. On the effect of the nozzle design on theperformances of gas-liquid cylindrical cyclone separators. IntJ Multiphase Flow. 2014;58:15-26. Available from: https://doi.org/ 10.1016/j.ijmultiphaseflow.2013.08.006.

15. Kha HM, Phuong NN, Nam NT. The effect of different geometrical configurations of the performances of Gas-Liquid Cylindrical Cyclone separators (GLCC). System Science and Engineering (ICSSE), 2017 International Conference. 2017;p. 646-651. Available from: https://doi.org/10.1109/ICSSE.2017. 8030955.

16. Kolla $\mathrm{S}$, et al. Structural integrity analysis of gas-liquid cylindrical cyclone (GLCC) separator inlet. Journal of Energy Resources Technology. 2018;140. Available from: https://doi.org/ 10.1115/1.4038622.

17. Kataoka I, Serizawa A. Bubble flow;Available from: https://doi.org/10.1615/AtoZ.b.bubble_flow;http://www. thermopedia.com/content/8/.

18. Zeigarnik, Albertovich Y. Annular flow;Available from: https://doi.org/10.1615/AtoZ.a.annular_flow;http: //www.thermopedia.com/content/11/.

19. Jayanti, Sreenivas. Churn Flow;Available from: https://doi.org/10.1615/AtoZ.c.churn_flow;http://www. thermopedia.com/content/264/. 


\title{
Nghiên cứu thực nghiệm ảnh hưởng của các kiểu đầu vào hình tròn ảnh hưởng đến hiệu suất của bộ tách khí-lỏng GLCC
}

\author{
Hồ Minh Kha ${ }^{1}$, Nguyễn Thanh Nam ${ }^{2,}{ }^{*}$, Võ Tuyển ${ }^{3}$, Nguyễn Tấn Ken ${ }^{3}$
}

${ }^{1}$ Trường ĐH Su pham Kỹ thuật Thành phố Hồ Chí Minh, Việt Nam

${ }^{2} P T N$ Trọng điêm Điêu khiển số và Kỹ thuật Hệ thống (DCSELAB), Khoa Cơ khí, Truiơng ĐH Bách khoa, ĐHQG-HCM, Việt Nam

${ }^{3}$ Trường Đại học Công nghiẹp Thực phâm Thành phố Hố Chí Minh, Việt Nam

Liên hệ

Nguyễn Thanh Nam, PTN Trọng điểm Điều khiển số và Kỹ thuật Hệ thống (DCSELAB), Khoa Cơ khí, Trường ĐH Bách khoa, ĐHQG-HCM, Việt Nam

Email: thanhnam@dcselab.edu.vn

Lịch sủ

- Ngày nhận: 25-10-2019

- Ngày chấp nhận: 19-12-2019

- Ngày đăng: 31-12-2019

DOI : 10.32508/stdjet.v3iSI1.732

\section{Check for updates}

\section{Bản quyền}

๑ ĐHQG Tp.HCM. Đây là bài báo công bố mở được phát hành theo các điều khoản của the Creative Commons Attribution 4.0 International license.

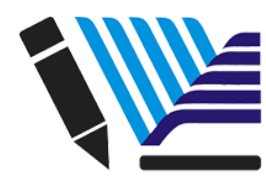

VNU-HCM Press

\begin{abstract}
TÓM TÁ́T
Bộ tách khílỏng GLCC là một công nghệ khá mới của ngành dầu khí. Thiết bị được nghiên cứu, phát triển và cấp bằng sáng chế bởi công ty Chevron và Đại học Tulsa (Hoa Kỳ). Nó được sử dụng như là sự thay thế tiêm năng cho các loại kiểu tách truyền thống đã được sử dụng trong hơn 100 năm qua. Ngoài ra, GLCC nhận được sự thu hút đáng kể với các công ty dầu khí trong những năm gần đây vì ảnh hưởng của giá dâu thế giới. Tuy nhiên, hành vi của các pha trong thiết bị rất nhanh, phức tạp và không ổn định gây khó khăn trong việc tăng hiệu suất tách riêng các pha. Nhiều nghiên cứu gần đây cho thấy rằng, hình học đâu vào là yếu tố quan trọng nhất ảnh hưởng trực tiếp đến hiệu suất làm việc của thiết bi. Tuy nhiên, cho đến nay, hầu hết các nghiên cứu về GLCC chỉ giới hạn với mô hình một đầu vào. Mục tiêu chính của nghiên cứu này là tìm hiểu sâu về tác động của các cấu hình hình học khác nhau của đầu vào kiểu tròn đối với hiệu suất của GLCC bằng phương pháp thực nghiệm với dòng hỗn hợp hai pha (khí-lỏng). Hai cấu hình đầu vào khác nhau được xây dựng, đó là: Một đầu vào kiểu tròn và hai đầu vào kiểu tròn đối xứng. Từ kết quả thực nghiệm, chúng tôi đề xuất sử dụng kiểu hai đầu vào ống tròn đối xứng để nâng cao hiệu suất tách pha.

Từ khoá: Thiết bị tách khí-lỏng, GLCC, Cyclone tách đa pha, hỗn hợp dòng đa pha
\end{abstract}

Trích dẫn bài báo này: Kha $H$ M, Nam N T, Tuyển $V$, Ken N T. Nghiên cứu thực nghiệm ảnh hưởng của các kiểu đầu vào hình tròn ảnh hưởng đến hiệu suất của bộ tách khí-lỏng GLCC. Sci. Tech. Dev. J. - Eng. Tech.; 2(SI1):SI164-SI173. 